\title{
WAKAF PRODUKTIF MENGENTASKAN PENGANGGURAN
}

\author{
Difi Dahliana
}

\section{Pendahuluan}

Pengangguran adalah orang yang tidak mempunyai pekerjaan akan tetapi sedang dalam usaha mencari pekerjaan; orang-orang yang tidak mempunyai pekerjaan tetapi tidak bermaksud untuk mencari pekerjaan tidak dimasukkan angkatan kerja. Tingkat pengangguran dihitung dari jumlah orang yang menganggur dibagi dengan seluruh angkatan kerja. ${ }^{1}$

Para ahli ekonomi telah membagi telah membagi tiga jenis pengangguran yakni pengangguran friksional, pengangguran struktural, pengangguran siklikal (siklis). ${ }^{23}$ Ada pula pengangguran yang hanya terdapat di negara-negara berkembang, yakni pengangguran tersembunyi (disguished unemployment), pengangguran musiman (seasonal unemployment), dan setengah menganggur (underemployment), yaitu keadaan pengangguran di mana seorang pekerja melakukan kerja jauh lebih rendah dari jam kerja normal ${ }^{4}$.

Pengangguran merupakan permasalahan sentral dalam masyarakat modern yang menimbulkan dampak ekonomis dan dampak sosial. Apabila tingkat pengangguran tinggi maka banyak sumber daya yang terbuang percuma dan pendapatan masyarakat berkurang. Dalam kondisi ini, tekanan ekonomi menjalar ke mana-mana sehingga mempengaruhi emosi masyarakat maupun rumah tangga. Bahkan pengangguran mengakibatkan memburuknya kesehatan baik secara fisik maupun psikologis ${ }^{5}$. Pengangguran juga mencermintan ketidakmerataan distribusi pendapatan di masyarakat. Pemerataan ekonomi dengan keadilan dan pemerataan pendapatan pada seluruh lapisan masyarakat

\footnotetext{
1 Paul A. Samuelson dan Wiliam D. Nordhaus, Makro Ekonomi, diterjemahkan oleh Haris Munandar, dkk (Jakarta: Erlangga, 1997), h. 291.

2 Wiliam A. Mceachern, Ekonomi Makro: Pendekatan Kontemporer, diterjemahkan oleh Sigit Triandaru (Jakarta: Thomson Learning Asia, 2000), h. 129.

${ }^{3}$ Sadono Sukirno. Makroekonomi Modern, (Jakarta: PT. Raja Grafindo Persada, 2000), h. 482483.

${ }^{5}$ Ibid, h. 288-290.
} 
akan mewujudkan pertumbuhan ekonomi yang mampu menggambarkan kesejahteraan yang sesungguhnya. ${ }^{6}$

Pengangguran merupakan problematika yang senantiasa ada di setiap tempat dan zaman, karena ia merupakan sunnatullah di dunia ini. Islam sebagai raḥmatan $\overline{l i}$ al-'alamin yang memiliki ajaran universal dan komprehensif telah menetapkan sejumlah aturan (dawābit) untuk menyikapi sunnatullah seperti ini. Banyak instrumen yang dapat diaplikasikan sebagai manifestasi ajaran tersebut di antaranya instrumen pilantropi seperti zakat produktif, wakaf produktif, dan sebagainya. Instrumen kemitraan seperti muḍarabah, musharakah, muzara'ah, dan sebagainya. Pemanfaatan tanah bebas melalui ihya al-mawat dan iqta’. Pada tulisan ini hanya akan dibahas mengenai wakaf sebagai instrumen untuk mengatasi persoalan pengangguran.

\section{Angka Pengangguran di Indonesia}

Pengangguran di Indonesia disebabkan dua faktor yakni faktor internal seperti kemalasan, kecacatan, rendahnya pendidikan dan kreativitas (kualitas SDM), dan faktor eksternal yakni ketidakseimbangan permintaan dan penawaran tenaga kerja, ketidaksesuaian hasil yang dicapai antara pendidikan dengan lapangan kerja, dan pengembangan sektor ekonomi non-riil.

Sebelum krisis ekonomi tahun 1997, tingkat pengangguran di Indonesia pada umumnya di bawah 5 persen dan pada tahun 1997 sebesar 5,7 persen. Tahun 2004 tingkat pengangguran mencapai angka 10,8 persen, pada tahun 2005 naik menjadi 11,2 persen. ${ }^{7}$

Situasi ketenagakerjaan pada bulan Februari 2008, hampir di seluruh sektor mengalami peningkatan jumlah pekerja jika dibandingkan dengan keadaan Februari 2007. Sektor yang mengalami peningkatan jumlah pekerja tertinggi berturut-turut yaitu: sektor jasa kemasyarakatan naik 1,82 juta orang serta sektor perdagangan naik 1,26 juta orang. Partisipasi perempuan dalam lapangan kerja

\footnotetext{
${ }^{6}$ Rusdiyah, Difi Dahliana, dan Dessy Maulina, "Tinjauan Islam Atas Pengaruh Pertumbuhan Ekonomi Terhadap Tata Guna Lahan Di Kota Banjarmasin," At-Taradhi: Jurnal Studi Ekonomi 7, no. 2 (15 Januari 2017): 173, https://doi.org/10.18592/at-taradhi.v7i2.2013.

${ }^{7}$ Amri Amir, “Inflasi dan Pengangguran di Indonesia”,
} 
meningkat signifikan. Selama Februari 2007-Februari 2008, jumlah pekerja perempuan bertambah 3,26 juta orang dan laki-laki hanya bertambah 1,21juta orang. Kenaikan pekerja perempuan terbesar terjadi di sektor perdagangan yaitu 1,51 juta orang dan sektor pertanian sebesar 740 ribu orang 8 .

Namun, berbagai pihak memperkirakan angka pengangguran pada tahun 2009 melonjak tajam akibat terjadinya krisis ekonomi global yang semakin dalam telah berdampak terhadap Pemutusan Hubungan Kerja (PHK) di Indonesia. Ribuan buruh terancam kehilangan pekerjaan terkait lemahnya ekspor barang akibat imbas dari krisis keuangan global. Menurut data tertulis yang telah dilaporkan kepada Menteri Tenaga Kerja dan Transmigrasi, angka PHK hingga Februari 2009 jumlahnya kurang lebih 29 ribu orang yang sudah di PHK, sedangkan yang mengajukan rencana PHK berjumlah 24 ribu dari sektor garmen, elektronik, perkayuan dan sebagainya. ${ }^{9}$ Menurut peneliti dari Pusat Penelitian Ekonomi (P2E) LIPI tingkat pengangguran di Indonesia diperkirakan akan naik sebesar $9 \%$ di tahun 2009 dari tahun lalu, sekitar $8,46 \%{ }^{10}$.

Pada tahun 2019, Badan Pusat Statistik (BPS) mencatat jumlah angkatan kerja pada Februari 2019 berjumlah 136,18 juta orang, naik 2,24 juta orang dibandingkan Februari 2018. Sedangkan pengangguran berjumlah 6,82 juta orang, menurun 50.000 orang dibanding Februari tahun sebelumnya. Struktur pekerjaan masih didominasi oleh sektor pertanian, kehutanan dan perikanan sebesar 29,46\%; sektor perdagangan sebesar 18,92\%; dan sektor industri pengolahan sebesar 14,09\%. Penyebab pengangguran adalah ketidakseimbangan antara penawaran dan permintaan tenaga kerja, ada ketidakcocokan antara keahlian yang dibutuhkan pencari kerja dengan keahlian yang dibentuk di sekolah. Hal ini dibuktikan dengan fakta bahwa berdasarkan tingkat pendidikan, lulusan SMK menyumbangkan pengangguran tertinggi yakni sebesar 8,63\% disusul oleh diploma sebesar 6,89\%.

\footnotetext{
8 Samsul Maarif, "Jumlah Pengangguran Menyusut", http://www.inilah.com/berita/ekonomi/ 2008/05/15/28472/jumlah-pengangguran-menyusut/, (15/05/2008).

9“"Menakertrans Soal Pengangguran \& PHK", http://WwW.kilasberita.com/amz/dtc, (16 Februari 2009)

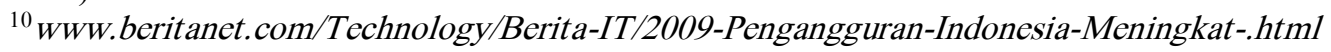




\section{Pandangan Islam tentang Pengangguran}

Islam memandang pengangguran merupakan fenomena yang senantiasa akan terjadi kapan pun dan dimana pun karena merupakan sunnatullah di muka bumi ini. Layaknya sunnatullah, terdapat orang kaya dan orang miskin, orang kuat dan orang lemah. Allah Swt berfirman, "Dan kami telah meninggikan sebagian mereka atas sebagian yang lain beberapa derajat, agar sebagian mereka dapat mempergunakan sebagian yang lain.” (QS. al-Zukrūf : 32) Jadi, itulah fitrah kehidupan di dunia ini. Namun upaya untuk menekan tingkat pengangguran harus terus dilakukan dengan serius meskipun tidak mungkin untuk menekannya sampai ke titik nol.

Banyak umat Islam yang salah paham dalam menyikapi fenomena sunnatullah seperti ini. Salah paham ini otomatis berakibat salah praktik terhadap beberapa ajaran seperti terhadap ungkapan atau istilah sehari-hari seperti sabar, qana'ah, tawakkal, insya Allah, zuhud, dan sesamanya. Istilahistilah ini dalam praktik sehari-hari umat Islam sering dijadikan landasan hidup, seolah menjustifikasi terhadap apa yang dilakukan. Namun sayangnya berkonotasi negatif, lamban, terbelakang, kemalasan dan semacamnya. Padahal arti yang sebenarnya harus berkonotasi positif, tidak menghambat kemajuan ekonomi dan perkembangannya. ${ }^{11}$

Islam selalu menekankan kepada umatnya agar menjadi orang yang memberi bukan meminta, melepaskan perbudakan bukan menjadi budak, dan lainnya. ${ }^{12}$ Dalam Islam bekerja untuk mencari rizki tidak dipandang sebagai aktifitas keduniawian semata tapi juga bermakna ibadah jika dilandasi dengan niat dan semangat yang lurus. Karena Islam menganjurkan umatnya menjadi kaya sehingga kekayaannya digunakan di jalan Allah, bahkan Allah memperingatkan umatnya agar tidak meninggalkan anak cucu dengan lemah dan tidak sejahtera, sebagaimana firman Allah surah al-Nisa ayat 9 yang artinya “dan hendaklah takut kepada Allah orang-orang yang seandainya meninggalkan di belakang (setelah) mereka anak-anak yang lemah, yang mereka khawatir terhadap (kesejahteraan) anak-anak tadi. Oleh karena itu, hendaklah mereka

\footnotetext{
${ }^{11}$ Qodri Azizy, Membangun Fondasi Umat Islam (Yogyakarta: Pustaka Pelajar, 2004), h. 33.

12 Ibid.
} 
bertakwa kepada Allah dan hendaklah mereka mengucapkan perkataan yang benar'13. Kalifah 'Umar ibn al-Ḳațab ketika mendengar jawaban orang-orang yang berdiam di masjid pada saat orang-orang sibuk bekerja dengan alasan bahwa mereka sedang bertawakal. Saat itu beliau berkata, "Kalian adalah orang-orang yang malas bekerja, padahal kalian tahu bahwa langit tidak akan menurunkan hujan emas dan perak." Kemudian Kalifah 'Umar. mengusir mereka dari masjid dan memberi mereka setakar biji-bijian. ${ }^{14}$

Suatu ketika datang kepada Rasulullah dari kalangan Anshar untuk meminta-minta (pengemis). Lalu Rasulullah bertanya kepada pengemis tersebut, "Apakah kamu mempunyai sesuatu di rumahmu?" Pengemis itu menjawab, "Saya mempunyai pakaian dan cangkir." Kemudian Rasulullah mengambil sebahagian pakaian dan cangkir tersebut untuk di jual kepada para sahabat. Salah seorang sahabat sanggup membeli barang-barang tersebut seharga dua dirham. Selanjutnya Rasulullah membagi uang yang di dapat tersebut untuk sebahagaian dibelikan keperluan kebutuhan keluarga pengemis tersebut dan sebahagian lagi dibelikan kapak sebagai sarana untuk berusaha mencari kayu bakar. Akhirnya dengan usahanya sang pengemis mendapatkan uang sebanyak sepuluh dirham.

Merujuk pada permasalahan diatas sebenarnya Islam telah mengajarkan cara yang paling ideal dalam mengatasi pengangguran. Merujuk pada permasalahan diatas sebenarnya Islam telah mengajarkan cara yang paling ideal dalam mengatasi pengangguran. Kita harus memberi pancing, jangan memberi umpan.

\section{Solusi Masalah Pengangguran dengan Wakaf Produktif}

Kekayaan tanah wakaf umat Islam Indonesia sangat besar, yaitu seluas 1.566.672.406 m2 dengan 403.845 lokasi. Dari jumlah tersebut sebanyak 75\% bersertifikat dan sekitar $10 \%$ berlokasi strategis dan potensial untuk

\footnotetext{
${ }^{13}$ Ibid, h. 55-56.

${ }^{14}$ Muhammad Nurmaksum, Khazanah Vol.I No.02, "Etos Kerja dalam Pandangan Islam", (IAIN Antasari: Banjarmasin, 2002), h. 161.
} 
dikembangkan secara ekonomi. Dilihat dari luasnya, tanah wakaf tersebut menyamai atau setidaknya mendekati luasnya Singapura. ${ }^{15}$

Potensi wakaf dalam bentuk uang juga sangat besar. Jumlah umat Islam yang terbesar di seluruh dunia merupakan aset besar untuk penghimpunan dan pengembangan wakaf uang. Jika 20 juta umat Islam Indonesia mau mengumpulkan wakaf tunai senilai Rp 100 ribu setiap bulan, maka dana yang terkumpul berjumlah Rp 24 triliun setiap tahun. Jika 50 juta orang yang berwakaf, maka setiap tahun akan terkumpul dana wakaf sebesar Rp 60 triliun. Jika saja terdapat 1 juta saja masyarakat muslim yang mewakafkan dananya sebesar Rp 100.000, per bulan maka akan diperoleh pengumpulan dana wakaf sebesar Rp 100 miliar setiap bulan (Rp 1,2 triliun per tahun). Jika diinvestasikan dengan tingkat return 10 persen per tahun maka akan diperoleh penambahan dana wakaf sebesar Rp 10 miliar setiap bulan (Rp 120 miliar per tahun). Sungguh suatu potensi yang luar biasa. ${ }^{16}$ Tentu ini menjadi modal yang sangat penting dan menjanjikan jika tanah-tanah dan dana wakaf tersebut dapat dikembangkan secara produktif.

Di Indonesia harta wakaf juga lebih banyak yang tidak menghasilkan (77 persen) daripada yang menghasilkan atau produktif (23 persen). Pemanfaatan terbesar harta wakaf adalah masjid (79 persen) daripada peruntukkan lainnya, dan lebih banyak berada di pedesaan (59 persen) daripada perkotaan (41 persen). Selain itu, diketahui bahwa jumlah nadzir yang bekerja secara penuh itu minim (16 persen). Umumnya mereka bekerja sambilan dan tidak diberi upah (92 persen). ${ }^{17}$

Untuk konteks Indonesia, lembaga wakaf yang secara khusus mengelola dana wakaf tunai dan beroperasi secara nasional itu berupa Badan Wakaf Indonesia (BWI). Tugasnya adalah mengkoordinir nazir-nazir yang sudah ada dan atau mengelola secara mandiri terhadap harta wakaf yang dipercayakan kepadanya, khususnya wakaf tunai. Hasilnya kemudian dipergunakan secara

\footnotetext{
${ }^{15} \mathrm{http} / /$ bimasislam.depag.go.id/?mod=publicservices\&op=detail\&id=38

${ }^{16}$ Cholil Nafis (Wakil Ketua Lembaga Bahtsul Masail PBNU), "Menghitung Potensi Wakaf Uang", http://malangraya.web.id/2009/05/04/menghitung-potensi-wakaf-uang/, (04 Mei 2009).

${ }^{17}$ Muhammad Cholil Nafis, "Menghitung Potensi Wakaf Uang Indonesia", http://malangraya.web.id/2009/05/04/menghitung-potensi-wakaf-uang/
} 
optimal untuk keperluan sosial, seperti meningkatkan pendidikan Islam, pengembangan rumah sakit Islam, bantuan pemberdayaan ekonomi umat dan atau pengembangan sarana prasarana ibadah. ${ }^{18}$

Secara umum tanah wakaf dikategorikan menjadi tiga yaitu tanah pedesaan, tanah perkotaan, dan tanah pinggir pantai. Berikut potensinya masingmasing: 19

Potensi Tanah Wakaf di Pedesaan

\begin{tabular}{|c|l|l|}
\hline No & \multicolumn{1}{|c|}{ Jenis Lokasi Tanah } & \multicolumn{1}{|c|}{ Jenis Usaha } \\
\hline 1 & Tanah persawahan & Pertanian, Tambak Ikan \\
\hline 2 & Tanah perkebunan & Perkebunan, Home Industry, Tempat wisata \\
\hline 3 & Ladang/padang rumput & Palawija, Real Estate, Pertamanan, Home Industry \\
\hline 4 & Tanah rawa & Perikanan, Tanaman sayuran \\
\hline 5 & Tanah perbukitan & $\begin{array}{l}\text { Tempat wisata, perkebunan, bangunan, home } \\
\text { industry, penyulingan air mineral }\end{array}$ \\
\hline
\end{tabular}

Potensi Tanah Wakaf di Perkotaan

\begin{tabular}{|c|l|l|}
\hline No & \multicolumn{1}{|c|}{ Jenis Lokasi Tanah } & \multicolumn{1}{|c|}{ Jenis Usaha } \\
\hline 1 & $\begin{array}{l}\text { Pingir jalan raya: dekat } \\
\text { jalan protokol }\end{array}$ & $\begin{array}{l}\text { Perkantoran, pusat perbelanjaan, apartemen, } \\
\text { hotel/penginapan, gedung pertemuan }\end{array}$ \\
\hline 2 & $\begin{array}{l}\text { Pinggir jalan raya: dekat } \\
\text { jalan utama }\end{array}$ & $\begin{array}{l}\text { Perkantoran, pertokoan, pusat perbelanjaan, rumah } \\
\text { sakit, rumah makan, sarana pendidikan, } \\
\text { hotel/penginapan, apartemen, gedung pertemuan, } \\
\text { pom bensin, apotek, wartel/warnwt, bengkel }\end{array}$ \\
\hline 3 & $\begin{array}{l}\text { Pinggir jalan raya: dekat } \\
\text { jalan tol }\end{array}$ & $\begin{array}{l}\text { Pom bensin, bengkel, rumah makan, outlet, warung, } \\
\text { wartel }\end{array}$ \\
\hline 4 & $\begin{array}{l}\text { Tanah yang dekat/dalam } \\
\text { perumahan }\end{array}$ & $\begin{array}{l}\text { Sarana pendidikan, klinik, apotek, outlet, warung } \\
\text { catering, BMT }\end{array}$ \\
\hline 5 & $\begin{array}{l}\text { Tanah dekat pusat } \\
\text { keramaian }\end{array}$ & $\begin{array}{l}\text { Perkantoran, rumah makan, bengkel, BPRS/BMT, } \\
\text { warung, wartel/warnet, klinik, jasa penitipan }\end{array}$ \\
\hline
\end{tabular}

Potensi Tanah Pinggir Pantai

\footnotetext{
${ }^{18}$ Direktorat Pemberdayaan Wakaf, Strategi Pengembangan Wakaf Tunai di Indonesia (Jakarta, 2007), h. 32-33.

19 Jaih Mubarok, Wakaf Produktif, (Bandung: Simbiosa Rektama Media, 2008), h. 76.
} 


\begin{tabular}{|c|l|l|}
\hline No & \multicolumn{1}{|c|}{ Jenis Lokasi Tanah } & \multicolumn{1}{c|}{ Jenis Usaha } \\
\hline 1 & Pinggir laut & Tambak ikan, objek wisata, home industry \\
\hline 2 & Rawa bakau & Perkebunan \\
\hline
\end{tabular}

Selanjutnya menurut data dari Direktorat Pemberdayaan Wakaf Kementerian Agama hingga Maret 2016, tanah wakaf di Indonesia telah mencapai $4.359 .443 .170 \mathrm{~m} 2$ yang terdiri dari 435.768 lokasi dengan rincian 287.160 lokasi telah bersertifikat dan 148.608 lokasi belum bersertifikat. Wakaf tunai hingga Oktober 2016 sudah ada 16 Lembaga Keuangan Syariah Penerima Wakaf Uang (LKS-PWU) yang beroperasi menerima wakaf tunai. Pengelolaan wakaf di Indonesia berdasarkan data dari Badan Wakaf Indonesia tahun 2016, penggunaan tanah wakaf di Indonesia terbagai beberapa sektor yaitu, 73,74\% masjid, 30,13\% mushola, 10, 61 sekolah, 4,23 \% makan, 2,98\% pesantren dan $8,32 \%$ fasilitas sosial lainnya. ${ }^{20}$

Apabila 200 juta jiwa umat Islam di Indonesia diberikan kesempatan untuk berwakaf sebesar Rp. 1.000/hari atau Rp. 30.000/bulan, maka potensi wakaf tunai di Indonesia dapat mendapai 7,2 triliun setiap bulannya. ${ }^{21}$ Dengan paradigma wakaf produktif, maka tanah wakaf yang berada di lokasi strategis tidak harus dimanfaatkan untuk pendirian masjid, sekolah atau lahan pemakaman. Di tengah persoalan pengangguran saat ini, sudah saatnya kehadiran wakaf dioptimalkan agar relevan sebagai problem solving dalam mengurangi tingkat pengangguran. Lahan potensial tersebut dikombinasi dengan dana wakaf (wakaf tunai) dapat dimanfaatkan secara produktif ke dalam bentuk usaha yang dapat menyerap tenaga kerja.

Pembangunan atau pengembangan usaha tidak harus terfokus di wilayah perkotaan, bukankah 59\% tanah wakaf berada diperdesaan. Berdasarkan kondisi geografis Indonesia, maka pertanian dan perikanan merupakan sektor unggulan yang sangat layak untuk di andalkan. Sayangnya, pembangunan sektor pertanian,

\footnotetext{
${ }^{20}$ Makhrus, "Dinamika Kebijakan Negara Dalam Pengelolaan Wakaf Di Indonesia," JSSH (Jurnal Sains Sosial Dan Humaniora) 2, no. 2 (8 Maret 2019): h. 211, https://doi.org/10.30595/ jssh.v2i2.3137.

${ }^{21}$ Makhrus, h. 211.
} 
misalnya, justru menurun dari tahun ke tahun. Data Departemen Pertanian menyebutkan, luas lahan pertanian pada periode 2000-2005 menurun menjadi 0,17 persen per tahun. Akibat lemahnya kebijakan, pemerintah tak dapat mengendalikan konversi lahan pertanian ke nonpertanian. Laju konversi saat ini mencapai 110.000 ha per tahun. ${ }^{22}$ Tidak dapat dipungkiri bahwa hal ini juga dipengaruhi oleh laju pertumbuhan ekonomi yang dapat meningkatkan urbanisasi sehingga kebutuhan lahan untuk kegiatan ekonomi dan perumahan menjadi semakin meningkat dan berakibat pada terjadinya perubahan tata guna lahan dengan melakukan alih fungsi khususnya lahan pertanian menjadi lahan industri dan pemukiman. ${ }^{23}$ Potensi wakaf yang di perdesaan dapat diberdayakan dalam melakukan revitalisasi ekonomi perdesaan, selain menghalau urbanisasi masyarakat desa untuk mencari pekerjaan di kota hal ini juga akan memobilisasi ekonomi perdesaan.

\section{Simpulan}

Fenomena pengangguran merupakan sunnatullah di dunia ini agar manusia dapat saling membantu dan melengkapi satu sama lainnya. Banyak instrumen yang dapat diaplikasikan sebagai manifestasi ajaran tersebut salah satunya adalah wakaf. Dalam mengatasi pengangguran jangan sekedar memberikan umpan, atau sekedar pancing tetapi harus berjalan keduanya sekaligus. Potensi wakaf di Indonesia yang sangat besar akan efektif mengurangi pengangguran di desa dan di kota jika dimanfaatkan dan diberdayakan secara produktif.

\section{Bibliography}

Azizy, Qodri. Membangun Fondasi Umat Islam, Yogyakarta: Pustaka Pelajar, 2004.

Direktorat Pemberdayaan Wakaf, Strategi Pengembangan Wakaf Tunai di Indonesia, Jakarta, 2007.

\footnotetext{
22 Aditya L Djono, "Menanti New Deal Perekonomian Nasional”, http://www. koranindonesia.com/2008/08/13/menanti-new-deal-perekonomian-nasional/,(13 Agust us 2008). ${ }^{23}$ Rusdiyah, Dahliana, dan Maulina, "Tinjauan Islam Atas Pengaruh Pertumbuhan Ekonomi Terhadap Tata Guna Lahan Di Kota Banjarmasin," h. 174.
} 
Djono, Aditya. "Menanti New Deal Perekonomian Nasional", http://WwW.koranindonesia.com/2008/08/13/menanti-new-dealperekonomian-nasional/.

Gobar, "Triple Track Strategy: Upaya Mengurangi Pengangguran dan Kemiskinan".

Haroen, Nasrun. Fiqih Muamalah, Jakarta: Gaya Media Pratama, 1998.

Ishaq, Abi. al-Tanbih fi al-Fiqh al-Syafi'i, Beirut: Dar al-Kutub al-Alamiyah, 1995.

Karim, Adiwarman Azwar. Bank Islam: Analisis Fiqih dan Keuangan, Jakarta: PT. Raja Grafindo Persada, 2004.

Maarif, Samsul. "Jumlah Pengangguran Menyusut", http://www.inilah.com/ berita/ekonomi/2008/05/15/28472/jumlah-pengangguran-menyusut/, (15 Mei 2008).

Makhrus. "Dinamika Kebijakan Negara Dalam Pengelolaan Wakaf Di Indonesia." JSSH (Jurnal Sains Sosial Dan Humaniora) 2, no. 2 (8 Maret 2019): 209-224-224. https://doi.org/10.30595/jssh.v2i2.3137.

Mceachern, Wiliam A. Ekonomi Makro: Pendekatan Kontemporer, diterjemahkan oleh Sigit Triandaru, Jakarta: Thomson Learning Asia, 2000 .

Mubarok, Jaih. Wakaf Produktif, Bandung: Simbiosa Rektama Media, 2008.

Nurmaksum, Muhammad. Khazanah Vol.I No.02, "Etos Kerja dalam Pandangan Islam”, IAIN Antasari: Banjarmasin, 2002.

Ridwan, Muhammad. "Manajemen Bait al-Māl Wa Tamwil (BMT)", Yogyakarta: UII Press, 2004.

Rusdiyah, Difi Dahliana, dan Dessy Maulina. “Tinjauan Islam Atas Pengaruh Pertumbuhan Ekonomi Terhadap Tata Guna Lahan Di Kota Banjarmasin." At-Taradhi: Jurnal Studi Ekonomi 7, no. 2 (15 Januari 2017): 163-74. https://doi.org/10.18592/at-taradhi.v7i2.2013.

Samuelson, Paul A. dan Wiliam D. Nordhaus, Makro Ekonomi, diterjemahkan oleh Haris Munandar, dkk. Jakarta: Erlangga, 1997.

Sukirno, Sadono. Makroekonomi Modern, Jakarta: PT. Raja Grafindo Persada, 2000. 